\title{
Treatment patterns and economic burden of sickle-cell disease patients prescribed hydroxyurea: a retrospective claims-based study
}

Nirmish Shah', Menaka Bhor ${ }^{2}$, Lin Xie ${ }^{3,4^{*}}$ (D) Rashid Halloway², Steve Arcona ${ }^{2}$, Jincy Paulose ${ }^{2}$ and Huseyin Yuce ${ }^{4}$

\begin{abstract}
Background: This study aimed to evaluate sickle-cell disease (SCD) treatment patterns and economic burden among patients prescribed hydroxyurea (HU) in the US, through claims data.

Methods: SCD patients with pharmacy claims for HU were selected from the Medicaid Analytic Extracts (MAX) from January 1, 2009 - December 31, 2013. The first HU prescription during the identification period was defined as the index date and patients were required to have had continuous medical and pharmacy benefits for $\geq 6$ months baseline and 12 months follow-up periods. Patient demographics, clinical characteristics, treatment patterns, health care utilization, and costs were examined, and variables were analyzed descriptively.

Results: A total of 3999 SCD patients prescribed HU were included; the mean age was 19.24 years, most patients were African American (73.3\%), and the mean Charlson comorbidity index (CCI) score was 0.6. Asthma (20.3\%), acute chest syndrome (15.6\%), and infectious and parasitic diseases (20\%) were the most prevalent comorbidities. During the 12-month follow-up period, 58.9\% ( $N=2357)$ of patients discontinued HU medication. The mean medication possession ratio (MPR) was 0.52 , and $22.3 \%$ of patients had MPR $\geq 80 \%$. The average length of stay (LOS) for SCD-related hospitalization was 13.35 days; $64 \%$ of patients had $\geq 1$ SCD-related hospitalization. The mean annual total SCD-related costs per patient were $\$ 27,779$, mostly inpatient costs $(\$ 20,128)$.
\end{abstract}

Conclusions: Overall, the study showed the patients had significant unmet needs manifest as poor medication adherence, high treatment discontinuation rates, and high economic burden.

Keywords: Hydroxyurea, Adherence, Discontinuation, Health care, Cost, Utilization

\section{Background}

Sickle-cell disease (SCD) consists of a group of rare genetic blood disorders characterized by a single missense mutation (Glu6Val) in the $\beta$-globin gene. The mutated hemoglobin in SCD, known as sickle hemoglobin (HbS), is less soluble and prone to polymerization upon deoxygenation, causing red blood cell sickling, which contributes to numerous other complications [1-3], as SCD progresses early on into a systemic disease. Vaso-occlusion is the primary indicator of SCD and can lead to serious acute and chronic

\footnotetext{
* Correspondence: Ixie@citytech.cuny.edu

${ }^{3}$ STAinMED Research, Ann Arbor, MI, USA

${ }^{4}$ New York City College of Technology (CUNY), New York, NY, USA

Full list of author information is available at the end of the article
}

complications; vascular dysfunction, inflammation, and Pselectin mediated cell-to-cell and cell-to-endothelium adhesion play an important role in the pathophysiology of SCD vaso-occlusive crisis (VOC), which is the most common clinical manifestation of SCD. Every VOC increases morbidity, and can result in organ damage or failure, acute chest syndrome (ACS), stroke, end-organ damage, or death [4-12]. The Centers for Disease Control and Prevention has estimated that 100,000 Americans are burdened with SCD, and in newborn infants it occurs most frequently among African-Americans [13]. Most notably, SCD has been associated with high physical and economic burden [14].

(c) The Author(s). 2019 Open Access This article is distributed under the terms of the Creative Commons Attribution 4.0 International License (http://creativecommons.org/licenses/by/4.0/), which permits unrestricted use, distribution, and reproduction in any medium, provided you give appropriate credit to the original author(s) and the source, provide a link to the Creative Commons license, and indicate if changes were made. The Creative Commons Public Domain Dedication waiver (http://creativecommons.org/publicdomain/zero/1.0/) applies to the data made available in this article, unless otherwise stated. 
Among SCD-related complications, VOC events have long been identified as a higher risk factor for death and the most common cause of hospital admission among SCD patients [15]. A 5-year study carried out using Florida Medicaid program data estimated that SCD patients had an average of 3.7 inpatient hospitalizations and 24.1 hospital days during the study period, with roughly $84 \%$ attributable to SCD-related diagnoses [16].

Currently, treatment and prevention options for VOCs are limited. It was not until the 1990s that the efficacy of hydroxyurea (HU) was first demonstrated in the prevention of VOCs [17]. In the US, HU was first approved by the FDA for use in the adult SCD population in 1998, and was recently approved for use in the pediatric SCD population in 2017 [18]. HU affects certain cells in the body, such as cancer cells and sickled red blood cells. It is used to treat cancers including chronic myeloid leukemia, ovarian cancer, and certain types of skin cancer such as squamous cell cancer of the head and neck. $\mathrm{HU}$ is also used palliatively to reduce pain episodes and the need for blood transfusions in people with sickle cell anemia, although it will not cure sickle cell anemia [19]. HU's mechanism of action (MOA) includes increasing the concentration of fetal hemoglobin, lowering the number of circulating leukocytes and reticulocytes, and decreasing their expression of adhesion molecules, thereby decreasing vascular occlusion. Other MOAs include increasing the size of the reticulocytes and improving cellular deformability, which increases blood flow and reduces vaso-occlusion and its associated complications. Furthermore, metabolism of HU releases nitric oxide, which can cause local vasodilation $[20,21]$. HU has been proven to effectively decrease the frequency of pain episodes and other acute complications in multiple randomized controlled trials [22]. Studies have shown that $\mathrm{HU}$ can be used as a substitute for chronic transfusions for the prevention of primary stroke among high-risk SCD pediatric patients with abnormal transcranial doppler (TCD) flow velocity [23, 24]. Also, observational studies have shown a relationship between HU use and decreased rates of hospitalization and blood transfusions $[25,26]$. More recently, the FDA approved oral L-glutamine therapy for SCD patients aged 5 years and older to reduce the number of acute complications associated with the blood disorder [27]; while this medication's MOA is not well understood, it is believed to result from a reduction of intracellular oxidation damage [28]. Adverse events associated with HU include GI symptoms such as loss of appetite, nausea, constipation and diarrhea; other symptoms include infection and bleeding [19].

VOCs lead to significant health care utilization and are the most common cause of emergency room (ER) visits and hospital admissions among SCD patients, with total medical costs exceeding $\$ 1.1$ billion in the US annually [16]. A US study using the Healthcare Cost and Utilization Project (HCUP) database was conducted to assess nationwide hospitalizations for SCD patients from 1994-2004, and estimated the annual direct hospitalization-related costs for SCD at \$488 million [29]. Another study in 2015 estimated the average cost per patient-month at $\$ 1389$, with a lifetime cost of care of approximately $\$ 460,000$ per patient with SCD [16]. The Bou-Maroun et al. analysis in 2018 determined that annual health care expenditures for SCD hospitalization resulted in costs over $\$ 900$ million, with a median hospitalization cost of $\$ 14,337$ per stay per patient [30]. Blinder et al. examined age-related treatment patterns among SCD patients and the associated complications and health care costs; their results showed that quarterly total health care costs per patient ranged from $\$ 11,913-\$ 11,957$ among patients who received $\geq 10$ blood transfusions [31].

Several studies that have examined the cost-effectiveness of $\mathrm{HU}$ support the advantages of $\mathrm{HU}$ use for clinical and economic benefits [26]. One study observed that HU use among pediatric patients resulted in reduced hospitalization and decreased health care costs [32]. Notably, studies have also shown that there is underutilization of $\mathrm{HU}$ among SCD patients, considering the significant efficacy of the drug [33]. However, few analyses have examined HU treatment patterns among SCD patients, and none have examined $\mathrm{HU}$ treatment patterns in a real-world setting. To demonstrate real-world treatment patterns of SCD patients prescribed $\mathrm{HU}$, this study descriptively evaluated treatment patterns and the economic burden of SCD patients who were prescribed HU in the US Medicaid database population.

\section{Methods}

\section{Data source}

This was a retrospective, descriptive study of the characteristics and treatment patterns of SCD patients prescribed HU during the period of 01JAN2009 through 31DEC2013, using the US Medicaid population database.

The MAX data system contains extensive individuallevel information on the characteristics of Medicaid enrollees in all 50 states and the District of Columbia, as well as the services used during a calendar year. Specifically, MAX consists of 1 personal summary file and 4 claims files that provide fee-for-service (FFS) claims, managed care encounter data, and premium payments. The study included FFS patients from all available states and managed care enrollees who resided in 14 states with the most relatively complete data available: Arizona, California, Indiana, Kansas, Kentucky, Minnesota, Nebraska, New Jersey, New Mexico, New York, Oregon, Tennessee, Texas, and Virginia. Service use among Managed Care enrollees is captured in encounter data. Patients who had 
dual eligibility with Medicare were not included in this study due to incomplete information in the MAX database.

\section{Patient selection}

Patients were included if they had $\geq 1$ pharmacy claim for HU during the identification period (01JUL2009 -01DEC2012); the first observed HU claim date was designated as the index date.

Patients were also required to have continuous health plan enrollment with medical and pharmacy benefits during the 6 months before the index date (baseline period) and 12 months after the index date (follow-up period). In addition, they were required to have $\geq 1$ diagnosis claim with SCD (International Classification of Diseases, Ninth Revision, Clinical Modification [ICD-9CM] codes: 282.41-282.42, 282.60-282.69) before the index date. Patients were excluded from the study if they were enrolled in a clinical trial during the study period (identified using ICD-9-CM: V70.7).

\section{Baseline measures}

Socio-demographics and clinical characteristics were evaluated for the baseline period including age, sex, race/ethnicity, geographical region, and Charlson Comorbidity Index (CCI) score. Baseline individual comorbid conditions were flagged including VOCs, pulmonary conditions (eg, ACS), cerebrovascular conditions (eg, stroke), hepatic and biliary conditions (eg, gallstones), splenic conditions (eg, splenic sequestration), and other conditions that commonly occur among SCD patients. Baseline all-cause health care resource utilization and costs were also identified by inpatient, outpatient (ER, office, other), and pharmacy visits. Health care costs were calculated only for patients enrolled in an FFS Medicaid plan.

\section{Outcome measures}

HU treatment patterns during the 12-month follow-up period were examined. HU discontinuation was defined as an observed refill gap of $\geq 90$ days between two subsequent prescriptions. The period from the index date to the discontinuation date was also examined. Sensitivity analysis using 30- and 60-day refill gaps were also conducted to measure discontinuation. Medication possession ratio (MPR) was calculated as the ratio of the total number of days of supply of HU to the total number of days in the follow-up period. The average daily dose was examined; dosing modification between the average $\mathrm{HU}$ daily dose during the follow-up period and on the index date was calculated. Treatments prescribed during the first 12 months of the follow-up period were identified. Monitoring patterns such as laboratory and radiology tests-in addition to all-cause and SCD-related health care resource utilizations and costs during the 1-year post-index date-were examined by facility type. The rate of complicated and uncomplicated VOCs was also examined, and health care costs were calculated only for patients enrolled in an FFS Medicaid plan.

\section{Statistical methods}

All variables were analyzed descriptively. Percentages and numbers were provided for dichotomous and polychotomous variables. Means and standard deviations were examined for continuous variables.

\section{Results}

\section{Baseline characteristics for the SCD patients prescribed HU}

A total of 3999 eligible patients met the study selection criteria and were included for analysis (Fig. 1). The mean age was 19.24 years (standard deviation $[\mathrm{SD}]=11.85$ ). Approximately half the study population $(51.8 \%)$ were aged under 18 years, and the majority (73.3\%) of SCD patients were African-American. The remaining 26.7\% were comprised of whites, Hispanics, and patients of other or unspecified ethnicity. In addition, the mean CCI score was 0.60 (Table 1 ).

More than half of the study population (53.6\%) had a VOC during the baseline period. Pulmonary conditions such as asthma (20.3\%), ACS (15.6\%), and upper respiratory tract infections (11.6\%) were the most prevalent comorbid conditions. Other frequent conditions observed among the study population included fever (31.4\%), infectious and parasitic diseases (20.0\%), and constipation (12.1\%, Table 1).

\section{Baseline health care utilization}

During the 6-month baseline period, all-cause health care utilization results showed that $90.0 \%$ had $\geq 1$ outpatient hospital visit, $78.4 \%$ had $\geq 1$ outpatient office visit, $71.1 \%$ had $\geq 1$ outpatient ER visit, and $60.3 \%$ had $\geq 1$ inpatient visit. The average length of stay (LOS) was 9 days, with a mean number of inpatient stays of 1.75 and 3.20 for outpatient ER visits (Fig. 2).

\section{Baseline health care costs}

Mean total costs for all-cause health care during the 6month baseline period were $\$ 19,194$; the primary cost drivers were inpatient $(\$ 12,806)$; pharmacy $(\$ 2371)$; outpatient (\$3563); and ER costs (\$406); other costs including laboratory visits and ambulatory costs amounted to $\$ 48$.

\section{Follow-up results}

\section{Treatment patterns for $S C D$ patients prescribed $H U$}

Treatment patterns during the 12-month follow-up period were measured. Using a 90-day treatment gap to define 


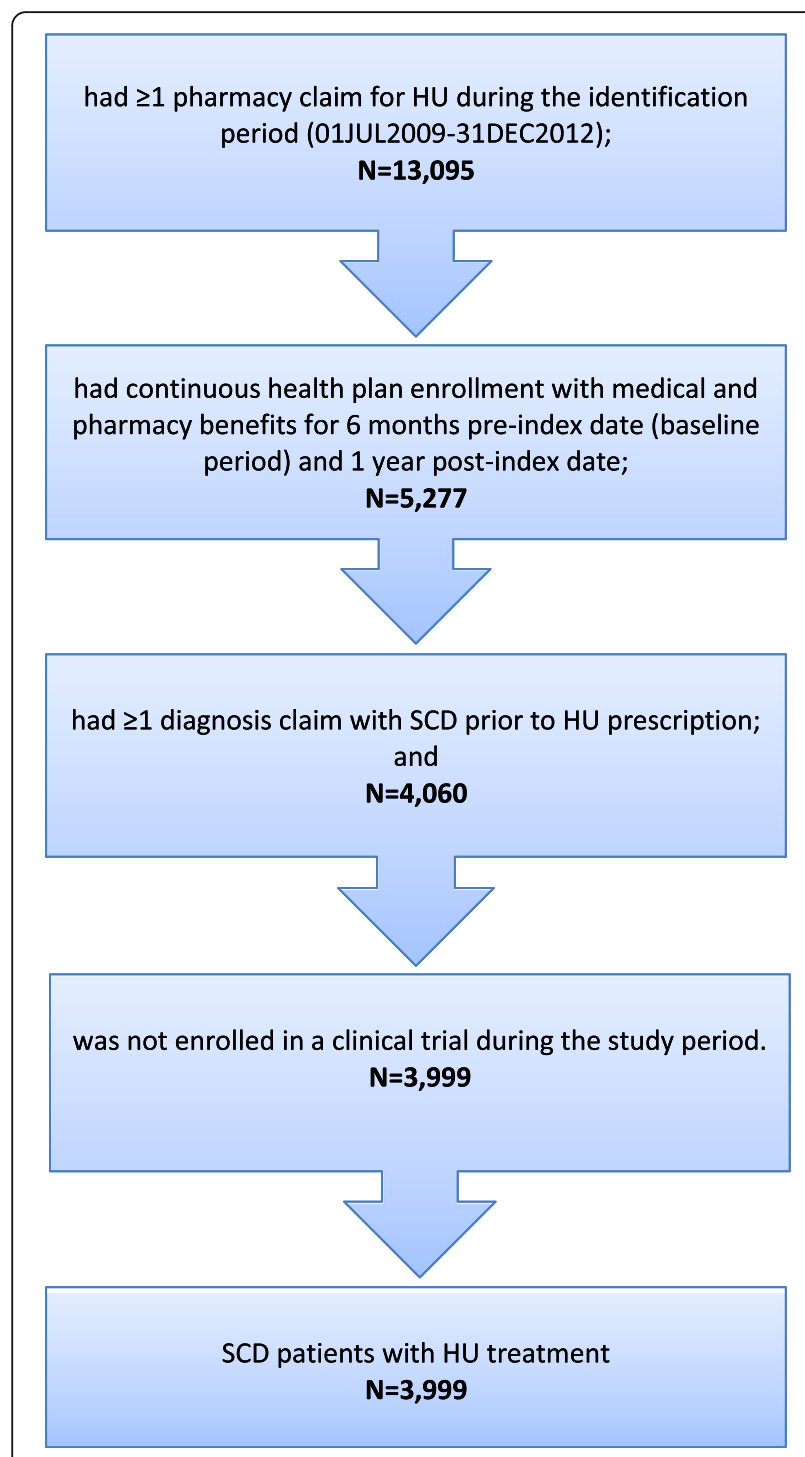

Fig. 1 Flow chart for patient selection criteria. HU: hydroxyurea; SCD: sickle cell disease

discontinuation, the rate of $\mathrm{HU}$ discontinuation was $58.9 \%$ $(N=2357)$. The average time-to-discontinuation was 202 days, with and $<50 \%$ of the SCD patients remaining on HU after 200 days (Fig. 3). During the 1-year follow-up period, $52.5 \%$ of the 2357 patients reinitiated HU. Using a 30-day gap to define discontinuation, the rate of HU discontinuation was $87.8 \%(N=3512)$, and $76.7 \%(N=2692)$ reinitiated HU. With a 60 -day gap, $72 \%(N=2878)$ of patients discontinued $\mathrm{HU}$, and $65 \%(N=1870)$ reinitiated HU (Additional file 1: Table S1).

The mean MPR was $0.52(\mathrm{SD}=0.36)$ among the overall HU patients; less than half (48.7\%) of the study population had MPR $\geq 50 \%$, and less than one-quarter (22.3\%) of patients had MPR $\geq 80 \%$ (Fig. 4).

The average index dose of HU was $980.6 \mathrm{mg}$ with an average decrease of $3.9 \mathrm{mg}$ during the follow-up period.
Table 1 Baseline demographic and clinical characteristics of SCD patients prescribed $\mathrm{HU}$

\begin{tabular}{|c|c|c|}
\hline \multirow[t]{3}{*}{ Patient characteristics } & \multicolumn{2}{|c|}{ Sickle cell patients prescribed $\mathrm{HU}$} \\
\hline & \multicolumn{2}{|c|}{$(N=3999)$} \\
\hline & N/Mean & $\% / S D$ \\
\hline Age (years) & 19.24 & 11.85 \\
\hline \multicolumn{3}{|l|}{ Age Group } \\
\hline$<2$ & 26 & $0.7 \%$ \\
\hline $2-5$ & 327 & $8.2 \%$ \\
\hline $6-11$ & 786 & $19.7 \%$ \\
\hline $12-17$ & 933 & $23.3 \%$ \\
\hline $18-30$ & 1272 & $31.8 \%$ \\
\hline $31-45$ & 501 & $12.5 \%$ \\
\hline$\geq 46$ & 154 & $3.9 \%$ \\
\hline \multicolumn{3}{|l|}{ Sex } \\
\hline Male & 2033 & $50.8 \%$ \\
\hline Female & 1966 & $49.2 \%$ \\
\hline \multicolumn{3}{|l|}{ Race/Ethnicity } \\
\hline White & 111 & $2.8 \%$ \\
\hline Black & 2933 & $73.3 \%$ \\
\hline Hispanic & 296 & $7.4 \%$ \\
\hline Other & 33 & $0.8 \%$ \\
\hline Unknown & 626 & $15.7 \%$ \\
\hline \multicolumn{3}{|l|}{ Geographic Region } \\
\hline Northeast & 1335 & $33.4 \%$ \\
\hline North Central & 590 & $14.8 \%$ \\
\hline South & 1501 & $37.5 \%$ \\
\hline West & 573 & $14.3 \%$ \\
\hline Charlson Comorbidity Index Score & 0.60 & 0.99 \\
\hline 0 & 2447 & $61.2 \%$ \\
\hline 1 & 1035 & $25.9 \%$ \\
\hline $2-3$ & 440 & $11.0 \%$ \\
\hline $4+$ & 77 & $1.9 \%$ \\
\hline \multicolumn{3}{|l|}{ Individual Comorbid Conditions ( $\geq 5 \%$ ) } \\
\hline Fever & 1255 & $31.4 \%$ \\
\hline Asthma & 811 & $20.3 \%$ \\
\hline Infectious and parasitic diseases & 798 & $20.0 \%$ \\
\hline Acute chest syndrome & 623 & $15.6 \%$ \\
\hline Constipation & 485 & $12.1 \%$ \\
\hline Upper respiratory tract infections & 462 & $11.6 \%$ \\
\hline Aseptic (avascular) bone necrosis & 307 & $7.7 \%$ \\
\hline Iron overload & 298 & $7.5 \%$ \\
\hline Gallstones & 214 & $5.4 \%$ \\
\hline Chronic pain & 205 & $5.1 \%$ \\
\hline Neoplasms benign and malignant & 198 & $5.0 \%$ \\
\hline Sepsis & 198 & $5.0 \%$ \\
\hline
\end{tabular}

HU hydroxyurea, $S C D$ sickle cell disease, $S D$ standard deviation

Other concomitant medications used after the index date included antibiotics (77.6\%), folic acid (75.1\%), and opioids (49\%; Fig. 5). Nearly $38.1 \%$ of the population had $\geq 1$ episode of blood transfusion with an average of 1.11 


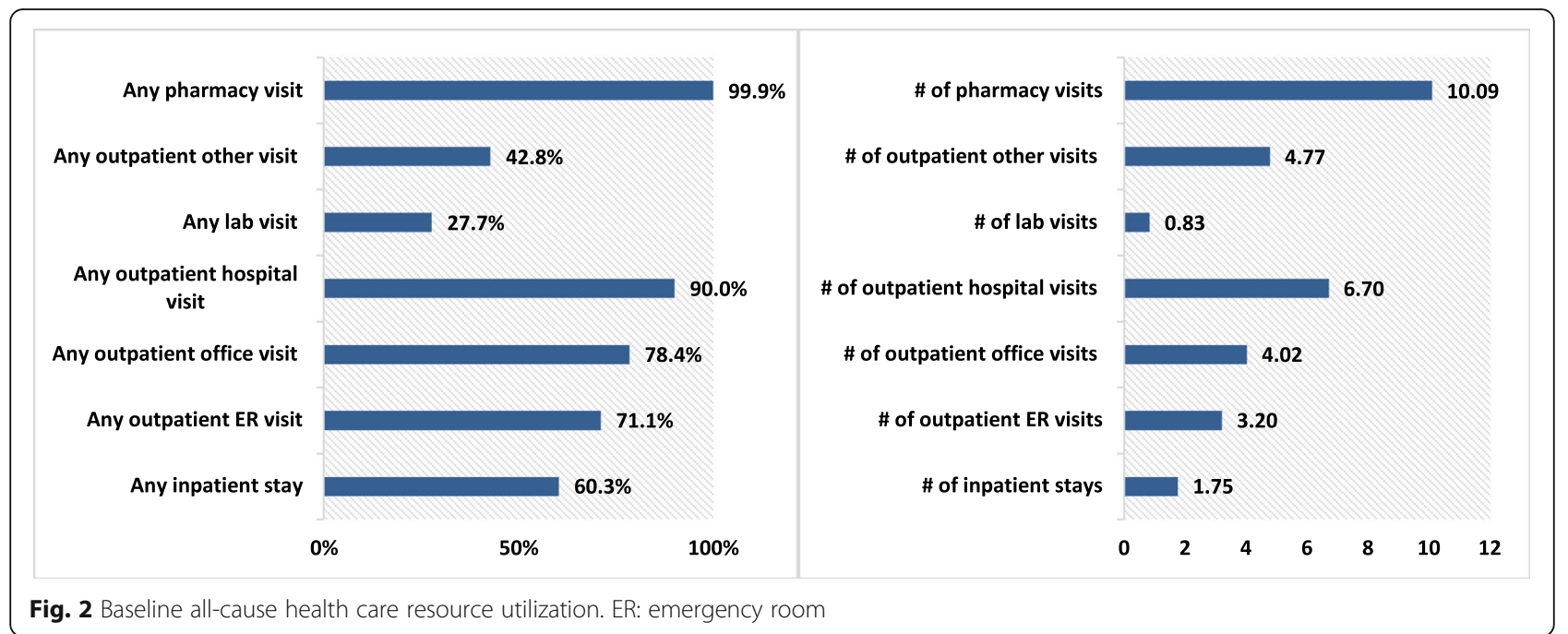

blood transfusions during the follow-up period; $25.0 \%$ were administered transcranial doppler ultrasonography. Only $4.4 \%$ of the population had pneumococcal vaccine, $2.9 \%$ had meningococcal vaccine, and $0.3 \%$ of the patients received a bone marrow transplant during the 12month follow-up period (Table 2).

\section{Monitoring patterns}

A majority (73.6\%) of the patients had a complete blood count performed, $69.6 \%$ had a chest $\mathrm{x}$-ray, $36.1 \%$ had an electrocardiogram, $31 \%$ had echocardiography, $29.2 \%$ had serum iron studies done, and $21 \%$ had an $x$-ray of an extremity carried out during the follow-up period. Other tests carried out included eye examination (22.7\%), plain abdominal $\mathrm{x}$-ray (14.7\%), and computerized tomography (CT) scan (8.5\%) during the follow-up period (Table 2). Approximately $99.1 \%$ of the patients who had a VOC presented with a form of complication, and $10.13 \%$ of the patients had ACS during the followup period.

\section{Health care resource utilization}

All-cause health care resource utilization results showed $65.2 \%$ of patients had $\geq 1$ inpatient visit during the follow-up period. The average number of inpatient visits was 2.83 , with a mean LOS of 14.69 days. In addition, $78.3 \%$ of the patients had $\geq 1$ ER visit with a mean of 6.20 visits and a median of 3 visits. Also, $94.5 \%$ had $\geq 1$ outpatient hospital visit (mean: 13.63 visits; median: 9 visits). About $86.5 \%$ had $\geq 1$ outpatient office visit (mean: 8.06 visits; median: 5 visits) during the 12-month followup period (Fig. 6).

The mean LOS for inpatient stays was 13.35 days for SCD-related hospitalization. Furthermore, $64 \%$ of the

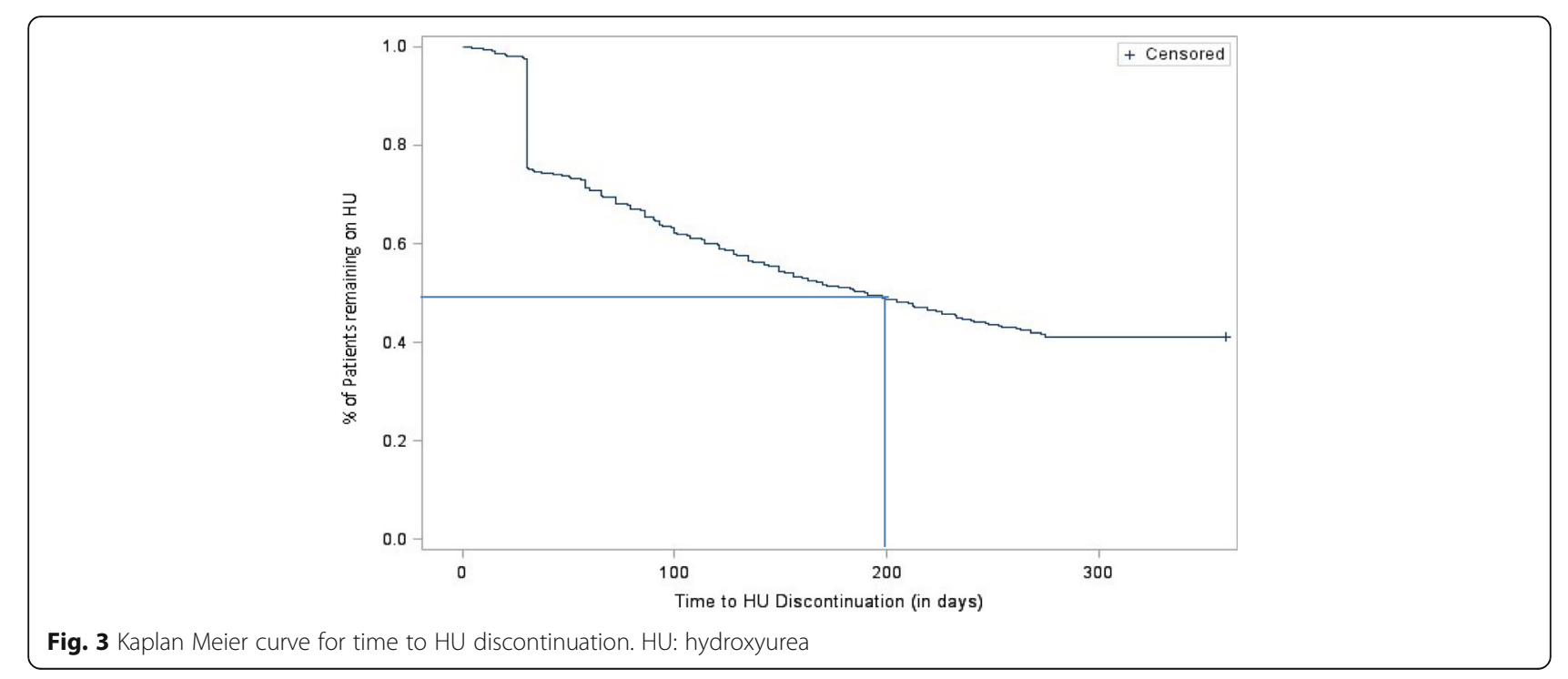




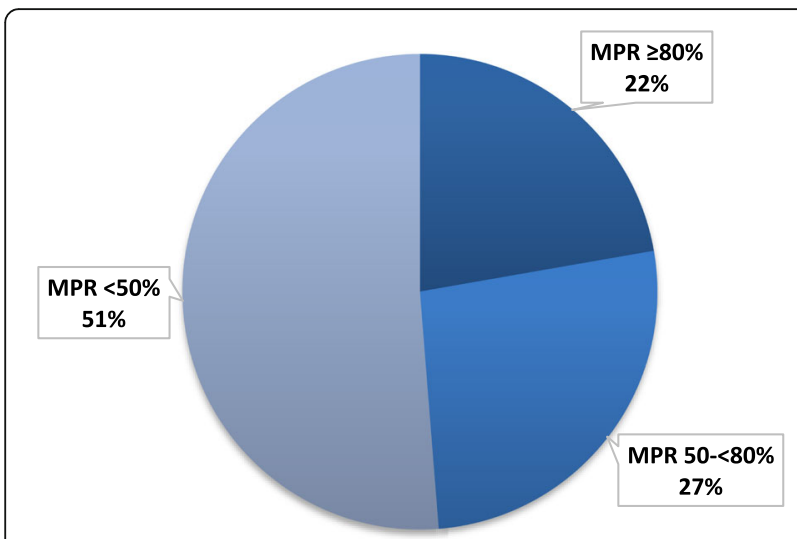

Fig. 4 MPR for SCD patients during the 12-month follow-up period. MPR: mean possession ratio

patients had $\geq 1$ SCD-related hospitalization and the mean number of visits was 2.5 . About $67.3 \%$ of the patients had $\geq 1$ SCD-related outpatient ER visit, with a mean number of 4.71 visits and median of 2 visits. About $64.3 \%$ of the patients had $\geq 1$ outpatient office visit with a mean of 3.86 and median of 2 visits. Also, $89.8 \%$ of patients had $\geq 1$ SCD-related outpatient hospital visit, with a mean of 9.97 visits and median of 7 visits during the 12-month follow-up period (Fig. 6).

\section{Health care costs}

Mean total all-cause health care costs during the 12month follow-up period were $\$ 36,253$ and the majority were due to inpatient costs $(\$ 23,000)$. In addition, pharmacy costs were $\$ 5038$, outpatient costs were $\$ 7417$, ER costs were $\$ 758$, and other costs including laboratory visit and ambulatory costs, amounted to \$40. SCDrelated health care costs during the 12-month follow-up period were $\$ 27,779$ (mean total costs), and the main cost driver was inpatient costs $(\$ 20,128)$. Pharmacy costs were $\$ 4656$, outpatient costs were $\$ 2399$, ER costs were
$\$ 579$, other costs, which included laboratory visits and ambulatory costs, amounted to \$18 (Fig. 7).

\section{Discussion}

This study provides real-world evidence of the demographic and clinical characteristics, treatment patterns, and economic burden of adult and pediatric SCD patients who were prescribed HU treatment. Although HU was only recently approved for pediatric use (December 2017), the results of this study showed that nearly half the study population of patients prescribed $\mathrm{HU}$ were aged under 18 years.

Although studies have shown that continuing regular HU treatment decreases or prevents complications of SCD [34], our study showed poor adherence to HU treatment. Specifically, findings included a mean MPR of 0.52 , less than half of the study population had an MPR $\geq 50 \%$, and less than one-quarter of patients had an MPR $\geq 80 \%$. The results are similar to the findings in another study that observed low HU adherence, in which $38 \%$ of SCD patients with $\mathrm{HU}$ treatment had an MPR $\geq 80 \%$ [35]. In addition, defining $\mathrm{HU}$ discontinuation using a 30 - to 90-day prescription gap between two subsequent prescriptions, the rate of $\mathrm{HU}$ discontinuation ranged from 58.9 to $87.8 \%$, and 52.5 to $76.7 \%$, among those who reinitiated HU. Specific reasons for discontinuation or poor HU adherence could not be ascertained in this study. However, a previous study carried out among younger SCD patients (aged 12-18 years) showed that half the participants had low HU adherence, and that patients who were more concerned about HU-related adverse events were more likely to report lower $\mathrm{HU}$ adherence [36]. Other studies have shown that, in addition to concerns such as HU-related adverse events, the costs and inconvenience associated with monitoring required during HU therapy as well as recall barriers and forgetfulness may contribute to the low HU compliance observed in most patients $[33,37,38]$. Furthermore,

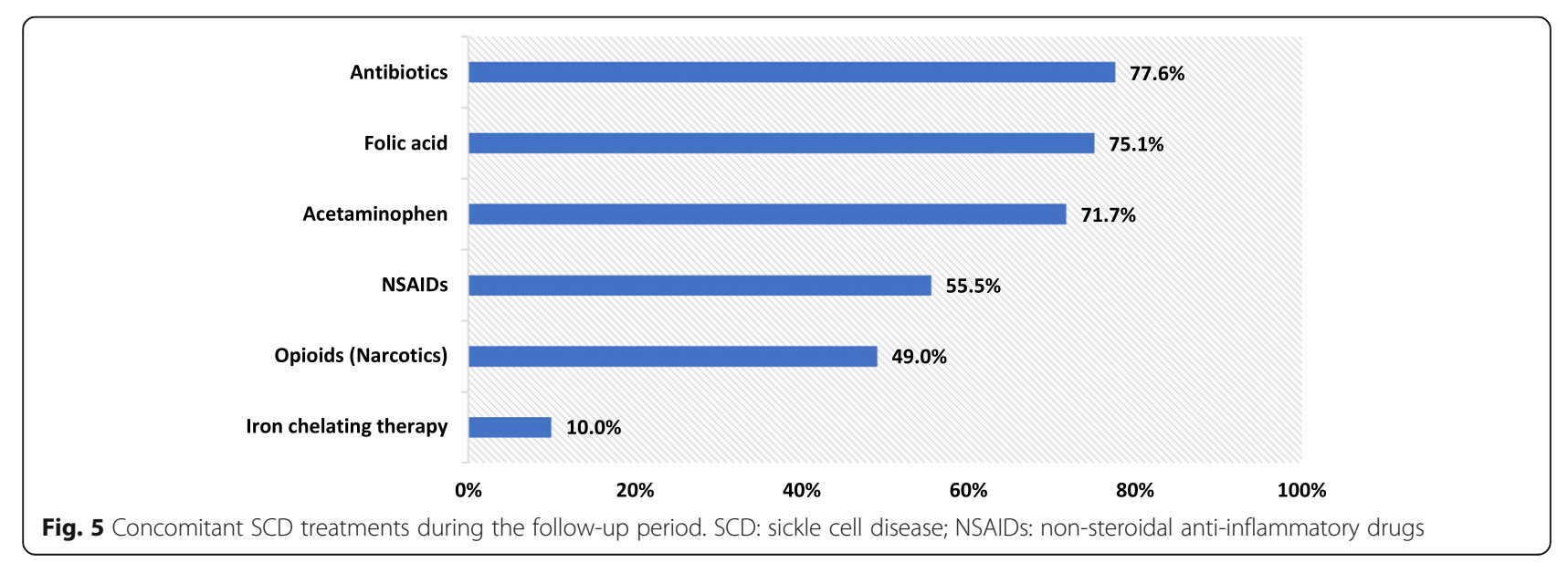


Table 2 Treatment patterns of SCD patients prescribed HU

\begin{tabular}{|c|c|c|}
\hline \multirow[t]{3}{*}{ Outcomes } & \multicolumn{2}{|c|}{ SCD patients prescribed HU therapy } \\
\hline & \multicolumn{2}{|c|}{$(N=3999)$} \\
\hline & N/Mean & $\% / S D$ \\
\hline \multicolumn{3}{|l|}{ HU Dose } \\
\hline HU index dose (mg) & 980.63 & 656.62 \\
\hline Dosing modification & -3.85 & 468.16 \\
\hline \multicolumn{3}{|c|}{ SCD Management (during the first 12 months) } \\
\hline \multicolumn{3}{|l|}{ Blood transfusions } \\
\hline \# of Patients & 1523 & $38.1 \%$ \\
\hline Number of blood transfusions & 1.11 & 2.28 \\
\hline Transcranial Doppler ultrasonography & 1001 & $25.0 \%$ \\
\hline Pneumococcal vaccine & 175 & $4.4 \%$ \\
\hline Meningococcal vaccine & 115 & $2.9 \%$ \\
\hline Bone marrow transplant & 11 & $0.3 \%$ \\
\hline \multicolumn{3}{|c|}{ Monitoring Patterns (during a 12-month period) } \\
\hline Chest X-ray & 2784 & $69.6 \%$ \\
\hline X-ray of extremity & 839 & $21.0 \%$ \\
\hline Abdominal plain film & 586 & $14.7 \%$ \\
\hline Computerized tomography & 341 & $8.5 \%$ \\
\hline Nuclear medicine studies & 158 & $4.0 \%$ \\
\hline Echocardiography & 1239 & $31.0 \%$ \\
\hline Electrocardiogram & 1444 & $36.1 \%$ \\
\hline Eye exams & 909 & $22.7 \%$ \\
\hline Complete blood count & 2945 & $73.6 \%$ \\
\hline Iron tests & 1167 & $29.2 \%$ \\
\hline
\end{tabular}

SCD sickle cell disease, $H U$ hydroxyurea, $S D$ standard deviation

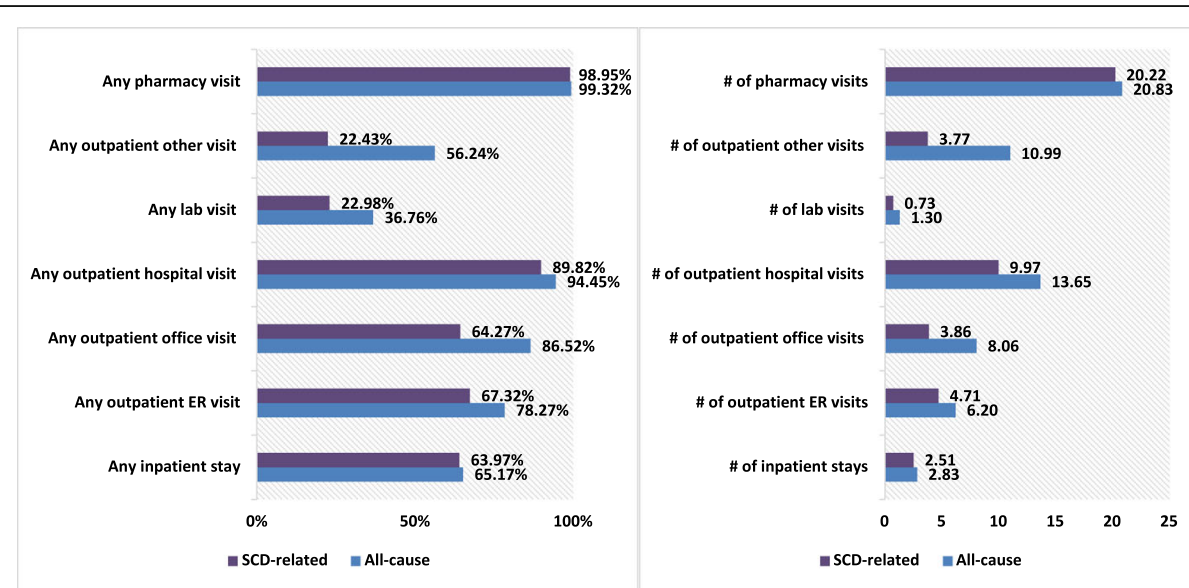

Fig. 6 Proportion of patients with numbers of visits for all-cause and SCD-related health care utilization. SCD: sickle cell disease; ER: emergency room 


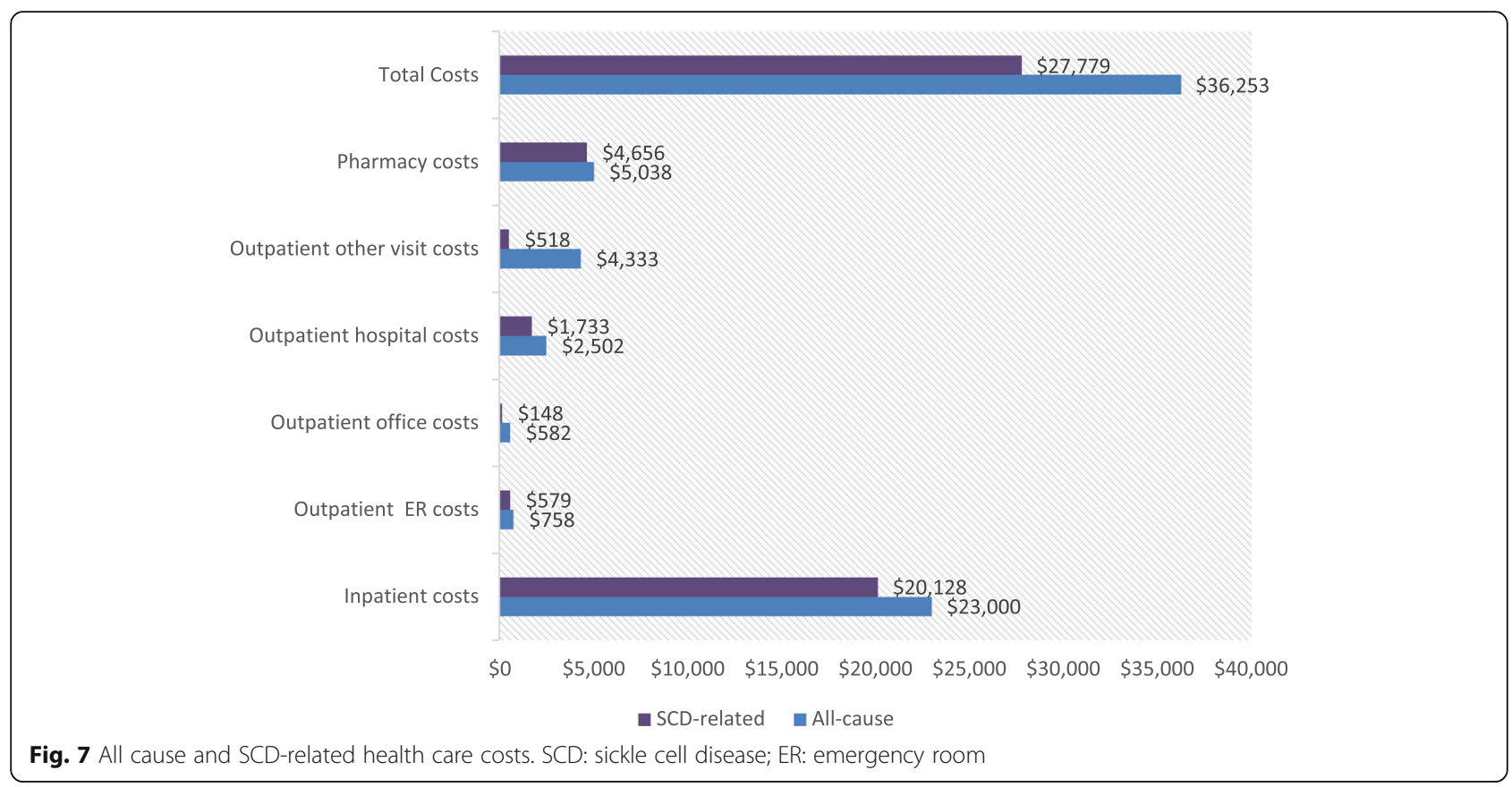

Badawy et al. showed that patients' concerns about potential adverse events associated with $\mathrm{HU}$, and concerns about overuse of HU medication in general, were associated with worse health-related quality of life [36]. A survey study of over 200 pediatric hematologists managing SCD patients revealed that the most common factors identified as barriers to $\mathrm{HU}$ use involved compliance. Most health care providers acknowledged that concerns with low HU compliance were low laboratory monitoring compliance, and low contraception compliance among female patients [39]. Furthermore, over 99\% of the SCD patients in this study had a form of complication associated with VOC, and the rate of ACS among study patients was $10.13 \%$. Although few studies have examined the rate of ACS in SCD patients, to our knowledge, no other study has examined the rate of ACS among SCD patients who were prescribed HU.

In addition to $\mathrm{HU}$ adherence, our study also examined monitoring patterns of SCD patients with HU use. The HU treatment guidelines for SCD patients recommend monitoring at least every 8-12 weeks. Evidence suggests that SCD patients treated with $\mathrm{HU}$ who received frequent monitoring had improved medication adherence and clinical outcomes [40]. A study showed monitoring of SCD patients on HU occurred every 4-6 weeks during escalation of therapy and every 8-12 weeks upon achievement of maximal tolerated dose (MTD). Monitoring included a physical examination, patient's history, and laboratory testing. The most commonly ordered laboratory tests used to monitor SCD patients on HU were complete blood counts, although liver function tests, renal function tests, and reticulocyte count are also frequently monitored [41]. However, this study's results showed that only $73.6 \%$ of SCD patients prescribed HU had $\geq 1$ complete blood count test post-HU initiation, $27.2 \%$ of the patients had $\geq 1$ serum iron study done, and the mean number of laboratory visits was 1.3 during the 12-month follow-up period.

This study also observed a high rate of morbidity associated with SCD, as a large proportion of all-cause hospitalizations (98.4\%), LOS (90.9\%) and ER admissions (86\%) were attributed to SCD. An ad hoc analysis carried out assessing Medicare SCD patients with or without a history of HU use showed that $85.8 \%$ of the LOS for allcause hospitalization and $82.9 \%$ of inpatient stays were attributed to SCD-related diagnoses. These results are similar to those from other studies that have analyzed SCD-related health care utilization, in which SCD patients were observed to have had an average of 3.7 inpatient hospitalizations and 24.1 hospital days, with roughly $84 \%$ attributable to $\mathrm{SCD}$-related diagnoses during the study period [16]. Also, SCD patients incurred higher costs $(76.6 \%$ of total health care cost attributed to SCD-related diagnoses). The results are again similar to the study by Kauf et al. that found $64 \%$ of costs were SCD-related [16]. HU adherence among SCD patients has also been associated with decreased risk of SCDrelated hospitalization, all-cause and SCD-related ER visits, and vaso-occlusive events [32, 42]. In addition, the difference in all-cause health care resource utilization in the baseline and follow-up periods showed a decrease in all-cause hospitalization, inpatient LOS, and outpatient ER visits. The decrease may have been due to the reduction in severe SCD-related complications that would 
warrant ER and inpatient visits, or longer hospitalizations possibly resulting from $\mathrm{HU}$ utilization during the follow-up period.

Few studies have examined the proportion of SCD patients who are prescribed $\mathrm{HU}$ as well as pain medication. Our study found that almost half of the patients were prescribed opioids (49.0\%) and nonsteroidal antiinflammatory drugs (NSAIDs) (55.5\%) during the followup period. Another study showed that older age, HU therapy, NSAID use, and frequent inpatient hospitalizations were associated with high-dose opioid use [43]. The high rate of pain medication utilization in this population of SCD patients may be because these SCD patients have a higher tendency to use pain medication because of high disease morbidity. Recommendations for HU use include SCD patients with $\geq 3$ moderate to severe pain episodes within a 12 -month period [22, 44, 45]. This study also observed a low rate of indications for pneumococcal and meningococcal vaccines during the 12-month follow-up period $(4.4$ and $2.9 \%$, respectively).

The abovementioned results on treatment patterns for vaccines are limited in that they may not have captured the true rate of SCD patients prescribed $\mathrm{HU}$ who were also administered these vaccines, since they are not given annually. It is possible that most patients received the recommended vaccine prior to the 12-month followup period, or their next vaccine dose may have occurred outside the study's 12-month follow-up period [46].

More generally, certain other limitations are associated with the use of any claims data, which are collected for the purpose of payment and not research. While medication adherence was measured using MPR, which is a widely accepted method for measurement in observational studies, the presence of a claim for a filled prescription does not indicate whether the medication was taken as prescribed or at all. Moreover, medications filled over-the-counter or provided as samples by the physician are not observed in claims data. In addition, the presence of a diagnosis code on a medical claim does not indicate a positive presence of disease, as the diagnosis code may be incorrectly coded or included as ruleout criteria rather than actual disease. Finally, claims data cannot capture certain demographic and clinical parameters.

For this study, results related to medication use and HU treatment patterns, among other results, may not be generalizable to other populations. The study setting is within the Medicaid population that consists of patients with disabilities, children of low-income families, pregnant women, parents of Medicaid-eligible children who meet certain income requirements, and low-income seniors [47]. These populations are more likely to have unmet needs in health care resource services. Individuals with dual eligibility for both Medicaid and Medicare were excluded, since data for these observations are not complete; together with the likelihood that many patients switched entirely from Medicaid to Medicare at age 65, this exclusion may have resulted in underrepresentation of patients aged 65 years or older, and therefore further limits the generalizability of the results to broader populations. Additionally, due to the limited availability of the data, the data of managed care plan patients only includes 14 states, and the study period until December 2013 was the most recent data at the time of study. SCD management guidelines have remained consistent in the past decade, so the findings of this study should remain valid in the current year. Furthermore, health care utilizations and costs can only be identified among patients enrolled in an FFS health plan. Therefore, the actual health care costs may be higher or lower than reported here, which may limit the ability of cost outcomes to be generalized to the entire Medicaid SCD population.

Finally, it is important to note that the present study was limited in scope to general associations between treatments and economic outcomes, and does not include certain parameters that may affect outcomes, such as associations between compliance and age and comorbidities, clinical guidelines, and certain clinical parameters that fell out of scope; nonetheless, the findings underscore the need for future investigation of more specific research questions.

\section{Conclusions}

Despite the positive disease-modifying effects of HU therapy, SCD patients treated with HU continue to have significant unmet needs in terms of medication adherence, high rates of treatment discontinuation, and high economic burden. Future research is needed to evaluate the reasons for discontinuation in a real-world data population, and to develop disease management strategies to help alleviate the SCD-related health care burden.

\section{Supplementary information}

Supplementary information accompanies this paper at https://doi.org/10. 1186/s12955-019-1225-7.

Additional file 1: Table S1. Sensitivity Analysis for Discontinuation Using 30- and 60-Day Refill Gaps.

\section{Abbreviations}

ACS: Acute chest syndrome; CCl: Charlson comorbidity index $C T$ : Computerized tomography; ER: Emergency room; FFS: Fee for service; HCUP: Healthcare Cost and Utilization Project; HU: Hydroxyurea; ICD-9-

CM: International Classification of Diseases, Ninth Revision, Clinical Modification; LOS: Length of stay; MAX: Medicaid Analytic Extracts; MOA: Mechanism of action; MPR: Medication possession ratio; NSAID: Nonsteroidal anti-inflammatory drug; SCD: Sickle-cell disease; TCD: Transcranial doppler; VOC: Vaso-occlusive crisis 


\section{Acknowledgments}

Not applicable

\section{Authors' contributions}

$N S, M B, L X$ and $H Y$ made substantial contributions to the conception and design of the study, and RH, SA, and JP made substantial contributions to the analysis and interpretation of the data. LX drafted the work and made substantive revisions. All authors approved and agree to take personal responsibility for the submitted version and any issues arising therefrom.

\section{Funding}

This study received funding from Novartis Pharmaceuticals.

\section{Availability of data and materials}

All data sets supporting the conclusions of this article are included within the article (and its additional files).

\section{Ethics approval and consent to participate}

Not applicable (de-identified data)

\section{Consent for publication}

Not applicable (see above)

\section{Competing interests}

$\mathrm{MB}, \mathrm{RH}, \mathrm{SA}$, and JP are employees of Novartis Pharmaceuticals. LX is an employee of STATinMED Research, a paid consultant to Novartis Pharmaceuticals

\section{Author details}

'Duke University, Durham, NC, USA. ${ }^{2}$ Novartis Pharmaceuticals Corporation, East Hanover, NJ, USA. ${ }^{3}$ STAinMED Research, Ann Arbor, MI, USA. ${ }^{4}$ New York City College of Technology (CUNY), New York, NY, USA.

Received: 18 January 2019 Accepted: 24 September 2019

\section{Published online: 16 October 2019}

\section{References}

1. Embury SH. The not-so-simple process of sickle cell vasoocclusion. Microcirculation. 2004;11(2):101-13.

2. Conran N, Franco-Penteado CF, Costa FF. Newer aspects of the pathophysiology of sickle cell disease vaso-occlusion. Hemoglobin. 2009; 33(1):1-16.

3. Chiang EY, Frenette PS. Sickle cell vaso-occlusion. Hematol Oncol Clin North Am. 2005;19(5):771-84.

4. Chakravorty S, Williams TN. Sickle cell disease: a neglected chronic disease of increasing global health importance. Arch Dis Child. 2015;100(1):48-53.

5. Ballas SK, et al. Definitions of the phenotypic manifestations of sickle cell disease. Am J Hematol. 2010;85(1):6-13.

6. Brousseau DC, et al. The number of people with sickle-cell disease in the United States: national and state estimates. Am J Hematol. 2010;85(1):77-8.

7. Powars DR, et al. Outcome of sickle cell anemia: a 4-decade observational study of 1056 patients. Medicine. 2005;84(6):363-76.

8. Health topics: who is at risk for sickle cell disease? National Heart, Lung, and Blood Institute Web site. https://www-nhlbi-nih-gov.proxy.lib.umich.edu/ health/health-topics/topics/sca/atrisk. Updated November, 2018. Accessed 24 Feb 2018.

9. Hebbel RP, Osarogiagbon R, Dhananjay K. The endothelial biology of sickle cell disease: inflammation and a chronic vasculopathy. Microcirculation. 2004;11(2):129-51.

10. Driss A, Asare KO, Hibbert JM, et al. Sickle cell disease in the post genomic era: a monogenic disease with a polygenic phenotype. Genomics Insights. 2009:2009(2):23-48.

11. Rees DC, Williams TN, Gladwin MT. Sickle-cell disease. Lancet. 2010; 376(9757):2018-31.

12. Kato GJ, Hebbel RP, Steinberg MH, Gladwin MT. Vasculopathy in sickle cell disease: biology, pathophysiology, genetics, translational medicine, and new research directions. Am J Hematol. 2009:84(9):618-25.

13. Sickle Cell Disease (SCD). Centers for Disease Control and Prevention Web site. Published 2016. Updated August, 2017. www.cdc.gov/ncbddd/ sicklecell/data.html. Accessed 28 Aug 2018.
14. Vekeman F, Sasane M, Cheng WY, et al. Adherence to iron chelation therapy and associated healthcare resource utilization and costs in Medicaid patients with sickle cell disease and thalassemia. J Med Econ. 2016;19(3):292-303.

15. Platt OS, Brambilla DJ, Rosse WF, et al. Mortality in sickle cell disease--life expectancy and risk factors for early death. N Engl J Med. 1994;330(23): 1639-44.

16. Kauf TL, Coates TD, Huazhi L, Mody-Patel N, Hartzema AG. The cost of health care for children and adults with sickle cell disease. Am J Hematol. 2009:84(6):323-7.

17. Chaine $B$, Neonato MG, Girot R, Aractingi $S$. Cutaneous adverse reactions to hydroxyurea in patients with sickle cell disease. Arch Dermatol. 2001;137(4): 467-70.

18. FDA approves hydroxyurea for treatment of pediatric patients with sickle cell anemia. US Department of Health and Human Services: US Food and Drug Administration Web site. https://www.fda.gov/Drugs/ InformationOnDrugs/ApprovedDrugs/ucm590096.htm. Accessed 20 Feb 2018.

19. Jinna S, Khandhar PB. Hydroxyurea Toxicity. [Updated 2019 Apr 4]. In: StatPearls [Internet]. Treasure Island (FL): StatPearls Publishing: 2019. Available from: https://www.ncbi.nlm.nih.gov/books/NBK537209/. Accessed 20 Feb 2018.

20. Ware RE. How I use hydroxyurea to treat young patients with sickle cell anemia. Blood. 2010;115(26):5300-11.

21. King SB. Nitric oxide production from hydroxyurea. Free Radic Biol Med. 2004:37(6):737-44

22. Nevitt SJ, Jones AP, Howard J. Hydroxyurea (hydroxycarbamide) for sickle cell disease. Cochrane Database Syts Rev. 2017:4:CD002202.

23. Ware RE, David BR, Schultz WH, et al. Hydroxycarbamide versus chronic transfusion for maintenance of transcranial doppler flow velocities in children with sickle cell anaemia-TCD With Transfusions Changing to Hydroxyurea (TWiTCH): a multicentre, open-label, phase 3, non-inferiority trial. Lancet. 2016:387(10019):661-70.

24. Adegoke SA, Macedo-Campos RS, Braga JAP, et al. Changes in transcranial Doppler flow velocities in children with sickle cell disease: the impact of hydroxyurea therapy. J Stroke Cerebrovasc Dis. 2018;27(2):425-31.

25. Nottage KA, Hankins JS, Smeltzer M, et al. Hydroxyurea use and hospitalization trends in a comprehensive pediatric sickle cell program. PLoS One. 2013:8(8):e72077.

26. Stallworth JR, Jerrell JM, Tripathi A. Cost-effectiveness of hydroxyurea in reducing the frequency of pain episodes and hospitalization in pediatric sickle cell disease. Am J Hematol. 2010;85(10):795-7.

27. FDA approves new treatment for sickle cell disease. FDA News Release. U.S Department of Health and Human Services: U.S. Food \& Drug Administration, Center for Drug Evaluation and Research Web site. Published July 7, 2017. https://www.fda.gov/NewsEvents/Newsroom/ PressAnnouncements/ucm566084.htm. Accessed 28 Mar 2018.

28. ENDARI ${ }^{\mathrm{TM}}$ highlights of prescribing information. Revised: July 2017. https:// www.accessdata.fda.gov/drugsatfda_docs/label/2017/208587s000lbl.pdf. Accessed 20 Dec 2018

29. Steiner CA, Miller JL. Sickle cell disease patients in U.S. hospitals, 2004 statistical brief \#21. Healthcare cost and utilization project (HCUP) statistical briefs. Rockville: Agency for Healthcare Research and Quality; 2006.

30. Bou-Maroun LM, Meta F, Hanba CJ, Campbell AD, Yanik GA. An analysis of inpatient pediatric sickle cell disease: incidence, costs, and outcomes. Pediatr Blood Cancer. 2018;65(1):e26758.

31. Blinder MA, Vekeman F, Sasane M, et al. Age-related treatment patterns in sickle cell disease patients and the associated sickle cell complications and healthcare costs. Pediatr Blood Cancer. 2013;60(5):828-35.

32. Wang WC, Oyeku SO, Luo Z, et al. Hydroxyurea is associated with lower costs of care of young children with sickle cell anemia. Pediatrics. 2013:132(4):677-83.

33. Brawley OW, Cornelius LJ, Edwards LR, et al. National institutes of health consensus development conference statement: hydroxyurea treatment for sickle cell disease. Ann Intern Med. 2008;148(12):932-8.

34. Paule I, Sassi H, Habibi A et al. Population pharmacokinetics and pharmacodynamics of hydroxyurea in sickle cell anemia patients, a basis for optimizing the dosing regimen. Orphanet J Rare Dis. 2011;6(1):30.

35. Candrilli SD, O'Brien SH, Ware RE, Nahata MC, Seiber EE, Balkrishnan R. Hydroxyurea adherence and associated outcomes among Medicaid enrollees with sickle cell disease. Am J Hematol. 2011;86(3):273-7.

36. Badawy SM, Thompson AA, Liem RI. Beliefs about hydroxyurea in youth with sickle cell disease. Hematol Oncol Stem Cell Ther. 2018;11:142. 
37. Platt OS. Hydroxyurea for the treatment of sickle cell anemia. $N$ Engl J Med. 2008;358(13):1362-9.

38. Badawy SM, Thompson AA, Penedo FJ, Lai JS, Rychlik K, Liem RI. Barriers to hydroxyurea adherence and health-related quality of life in adolescents and young adults with sickle cell disease. Eur J Hematol. 2017;98(6):608-14.

39. Brandow AM, Jirovec DL, Panepinto JA. Hydroxyurea in children with sickle cell disease: practice patterns and barriers to utilization. Am J Hematol. 2010;85(8):611-3.

40. Creary SE, O'Brien SH, Stanek J, et al. A retrospective review to determine if children with sickle cell disease receive hydroxyurea monitoring. Pediatric Qual Safety. 2017;2(3):e024

41. Phillips K, Healy L, Smith L, Keenan R. Hydroxyurea therapy in UK children with sickle cell anaemia-a single centre experience. Pediatr Blood Cancer. 2018;65:e26833 https://doi-org.proxy.lib.umich.edu/10.1002/pbc.26833.

42. Candrilli SD, O'Brien SH, Ware RE, et al. Hydroxyurea adherence and associated outcomes in Medicaid enrollees with sickle cell disease. Am J Hematol. 2011;86(3):2483-3.

43. Han J, Zhou J, Saraf SL, Gordeuk VR, Calip GS. Characterization of opioid use in sickle cell disease. Pharmacoepidemiol Drug Saf. 2017;27(5):479-86.

44. Tripathi A, Jerrell JM, Stallworth JR. Clinical complications in severe pediatric sickle cell disease and the impact of hydroxyurea. Pediatr Blood Cancer. 2011:56(1):90-4.

45. Agrawal RK, et al. Hydroxyurea in sickle cell disease: drug review. Indian J Hematol Blood Transfus. 2014;30(2):91-6.

46. Centers for Disease Control and Prevention. Use of 13-valent pneumococcal conjugate vaccine and 23-valent pneumococcal polysaccharide vaccine for adults with immunocompromising conditions: recommendations of the Advisory Committee on Immunization Practices (ACIP). MMWR Morb Mortal Wkly Rep. 2012;61(40):816.

47. Krieger JW, Connell FA, LoGerfo JP. Medicaid prenatal care: a comparison of use and outcomes in fee-for-service and managed care. Am J Public Health. 1992;82(2):185-90.

\section{Publisher's Note}

Springer Nature remains neutral with regard to jurisdictional claims in published maps and institutional affiliations.

Ready to submit your research? Choose BMC and benefit from:

- fast, convenient online submission

- thorough peer review by experienced researchers in your field

- rapid publication on acceptance

- support for research data, including large and complex data types

- gold Open Access which fosters wider collaboration and increased citations

- maximum visibility for your research: over $100 \mathrm{M}$ website views per year

At $\mathrm{BMC}$, research is always in progress.

Learn more biomedcentral.com/submissions 